\title{
O BROJNOM STANJU OSMANSKE VOJSKE U POHODU NA SINJ I ZAGORU 1715. GODINE PREMA TURSKIM IZVORIMA
}

U članku se upozorava na prvorazredne osmansko-turske izvore u svezi s opsadom Sinja 1715. godine. Preliminarnim iščitavanjem bilo je moguće ustanoviti da su sveukupne osmanske snage bile dvostruko manje od većine do sada korištenih procjena, a pod samim Sinjem vjerojatno je bilo tek oko četvrtine maksimalističkoga nagađanja.

Ključne riječi: Sinj 1715.; Osmanlije; sastav vojske; opskrba; Arhiv Predsjedništva vlade Istanbul.

Na znanstvenom skupu o 300-godišnjici pobjede nad Osmanlijama pod Sinjem $^{1} \mathrm{u}$ svojem prilogu nisam se mogao poslužiti brojčanim podatcima iz prvorazrednih osmanskih izvora, te sam morao više spekulativnim i neizravnim putem kritički suditi o predodžbama uvriježenim u historiografiji. Nešto kasnije objavljen je rad Lovorke Čoralić i Nikole Markulina u kojem se na temelju „kliometričkih" proračuna dolazi do rezultata dosta bliskih mojim nagađanjima. ${ }^{2}$ Sada je pak moguće osloniti se na izravno svjedočenje osmansko-turskih dokumenata ${ }^{3}$, pa to želim učiniti u obliku prethodnog priopćenja.

Radi se ojednom fermanu (carskoj zapovijedi) ${ }^{4}$ ijednom defteru („bilježnici“), obojemu iz vremena priprema i trajanja pohoda protiv mletačkih posjeda u Dalmaciji ${ }^{6}$ u kontekstu „Malog Morejskog rata“ (ljeto 1715. godine). Ferman se od-

1 Međunarodni znanstveni skup o 300. obljetnici slavne obrane Sinja 1715. godine, Sinj 2015.

2 Lovorka Čoralić - Nikola Markulin, Bitka za Sinj 1715. godine, Zbornik Odsjeka za povijesne znanosti Zavoda za povijesne i društvene znanosti Hrvatske akademije znanosti i umjetnosti, Zagreb 2016., 147180.

3 Građa (skenirana) zapravo mi je bila dostupna već neko vrijeme prije održavanja znanstvenog skupa, no bila je na neki način zagubljena u mojoj vlastitoj zbirci. Sada sam je, nasreću, iznova „otkrio“.

4 BOA, İE_AS___00067_06061.

5 Defter sadrži sedamnaest folija i dosta je teško čitljiv. BOA, D.BŞM.d - 01275-A.

6 Defter sadrži i manji broj zapisa nastalih nakon pohoda, uglavnom glede isplata raznim povjerenicima (od 26. siječnja do 3. ožujka 1716.). Stoga se može pretpostaviti da je u konačnom obliku nastao početkom 1716., spajanjem starijih i mlađih zapisa. 
nosi na tatarske postrojbe i njihovu opskrbu dok ne stignu na bojište, a upućen je povjerenicima i nadzornicima državnih skladišta na donjem Dunavu (skele Isakča i Tulča). Radi se o deset tisuća boraca, koji će se podijeliti na polovicu što će ratovati kao pomoć na fronti u jadranskome zaleđu, a druga će se polovica pridružiti trupama okupljenim u Makedoniji što kreću protiv Mlečana na Peloponezu.

Defter se pak primarno odnosi na plaće ${ }^{7}$ l logistiku vojske pod zapovijedanjem Mustafa-paše Čelića, pri čemu nisu obuhvaćene trupe iz bosanskog ejaleta jer spahije nisu primali plaću u gotovu, a za opskrbu su se morali pobrinuti sami. Za dostavu hrane bili su zaduženi pojedinci, niži zapovjednici i trgovci iz nekih kadiluka, nastanjeni u Bosanskom Brodu, Travniku, Pruscu i drugdje. I dok sada znamo točan broj „,vanjskih“ snaga, za bosanske postrojbe i dalje možemo samo nagađati, no ipak možemo poći od čvrstih parametara koji se odnose na vojni kapacitet ejaleta. Tako bi dosta blizu stvarnom stanju morala biti brojka do najviše petnaest tisuća aktivnih boračkih postrojbi, uglavnom pripadnika spahijske vojske uz moguć stanoviti udjel tvrđavskih posada i građana - dragovoljaca. Godinu dana ranije, 1714., vezir Numan-paša vodio je pohod na Crnu Goru s upravo toliko vojnika (15.000), a ta se brojka, posve realna, opet javlja u vrijeme banjolučkog boja 1737. To je sasvim dovoljno za spahijsku vojsku, te ne bi bilo opravdano zamišljati neki znatniji udjel tvrđavske, odnosno kapetanijske vojske. Tih je odreda u to vrijeme bilo nešto preko $16.000,{ }^{8}$ no oni su bili potrebni ondje gdje su služili, a ne da se krajiški tvrdi gradovi isprazne. Uostalom, serasker je pojačavao posade, a ne smanjivao. Tome, kako smo vidjeli, valja pridodati 5.000 Tatara kojima je zapovijedao „sultan“, dakle jedan od sinova krimskog hana Kaplan Giraya, 2.000 Albanaca pod vodstvom Mahmudoglu Tahir-paše sandžak-bega Dukađina, 500 leventi (dragovoljaca) konjanika i pješaka s područja Sofije, Niša i Kruševca, 1.044 "carskih leventi“ te 11.620 pripadnika isto tako "nebosanskih“ odreda, također pretežno dragovoljaca. ${ }^{9}$ Njihov je angažman bio utvrđen popisom Mustafa-paše i potvrdom vojnog kadije, dok je za skupinu iz tri rumelijske oblasti bio nadležan kruševački kadija. Dakle, to je vrlo blizu najnižoj mletačkoj procjeni od $40.000,{ }^{10} \mathrm{~s}$ tim da bi konačni broj morao biti

\footnotetext{
7 Najčešće sumarno u mjesečnim iznosima, uvećanim za 10\% (ondalık).

8 BOA, MAD 10301. fol. D 05091068.

9 „Levent“ od talijanskog „levantino“ znači razbijač, nevaljalac, štetočina i tome slično. Nosili su zelene prsluke. Doista ih se nije smatralo kvalitetnim trupama, a to se, čini se, u slučaju opsade Sinja i potvrdilo. Portin kontingent imao je 4.000 janičara, 400 džebedžija/oružara, 200 tobdžija, 80 toparabadžija (prijevoznika), svega: 4.680. Levente (rumelijske s 2.000 Albanaca) 7.740, svega: 12.420 Umanjeno za 800 vojnika na čuvanju tvrđava u pozadini, svega 11.620. 
nešto niži, jer je paša iz opreza manji dio vojnika poslao kao pojačanje u nekoliko tvrđava u bližoj i daljoj okolici te je istodobno morao izdvojiti sredstva za "napojnice“ (bahşiş) ${ }^{11}$ i popravke "nekih tvrđava na bosanskom serhadu/krajištu“, i to: Počitelj, Klobuk, ${ }^{12}$ Trebinje, Ljubuški - cisterna, Mostar, Kupres - palanka, Glamoč - parmakluk/palisade, Ključ - opkop/šarampov, Imotski - kule, Hutovo i Vidoška, Sarajevo - pokretni most tvrđave, Jajce - popravak krova oružarnice, Čačvina ${ }^{13}$, Nikšić, klanac Tupan, Gabela - kule, Struge - kula, palanka Župan Potok/Duvno, Livno. U tu skupinu troškova uvrštena je i stavka koja se odnosi na plaću majstora za popravak zatvarača topova (kamaci) korištenih za opsadu Sinja i prebačenih $\mathrm{u}$ Livno. ${ }^{14}$ Znatna sredstva izdvojena su za troškove skladišta hrane na skelama Šabac, Zvornik i Gradiška te u Banjoj Luci i Livnu. Prema obračunu troškova za plaće pekarima i njihovu zapovjedniku (serhabbazan) uz specifikaciju posla koji će obaviti za potrebe „bosanske vojske“ moći ćemo se u budućim istraživanjima približiti i stvarnom broju ejaletskih trupa. Obavijesni potencijal mnoštva podataka u svezi sa svim vrstama konja čini se na prvi pogled osobito vrijednim. Tako se vidi da su stotine tovarnih konja iz Korče i Soluna prevedene iz carske armije bosanskoj vojsci, u organizaciji kršćanskih poduzetnika (sermekardžija) Atnaša (?) i Janka. ${ }^{15}$ Brojku od petnaest tisuća „,teglećih životinja", prema mletačkom izvješću, vjerojatno također treba korigirati. Za sada je razvidno da su po kadilucima u Bosni prikupljena 1.543 teretna konja.

Odakle potječe nesklad između navedenih, doista čvrstih podataka i dvostruko većeg broja prema u najnovije vrijeme pronađenom mletačkome izvješću? ${ }^{16}$ Pri tome brojke koje se odnose na ejaletsku vojsku jesu nešto pretjerane, no u slučaju „,nebosanskih“ trupa prebačaj je vrlo velik. Nije nemoguće da se radi o kontaminaciji "dalmatinskih“ kvantitativnih podataka s onim „morejskima“. Osim toga, kada se u drugim prigodama, kao što je banjolučki boj 1737., govori o 40.000 pripadnika spahijske vojske (u mletačkome „maksimalističkom“ izvješću svega 24.000), moguće je da se mislilo na ukupni broj pripadnika spahijskog staleža, a taj je, zbog sustava tzv. odžakluk timara, obuhvaćao gotovo sve odrasle muškarce s načelnim pravom nasljeđivanja nadarbine, što je daleko više od broja aktualnih uživatelja. Napokon, vrlo je vjerojatno da je preuveličan i broj neboračkog oso-

\footnotetext{
11 Detaljno se nabraja materijal poput vapna, dasaka i čavala te pripadajući novčani izdatci.

12 Vjerojatno Klobuk u istočnoj Hercegovini.

13 Popravak cisterne (zbog moguće opsade!). Provijant za dodatne čuvare: 3.780 groša (riža, maslo, žito, dvopek).

14 Datum 7. rujna 1715

15 Na fol 5. Janko. Drugi put spomenut je „Yanko Arnavud“, sin Dima, mesar, stanovnik Travnika!

16 Archivio di Stato Venezia - ASVe, PTM, b. 556, no. 69, prilog 6. od 13. kolovoza.
} 
blja, jer, ako je suditi prema proporciji od $20 \%$ iz istog mletačkoga dokumenta, pomoćnog bi osoblja moglo biti $6.000-7.000$, a to nas na koncu opet približava „donjoj procjeni“, od oko 40.000. To nije usamljeni primjer. O brojnom stanju osmanske vojske koja je 1737. kod Banje Luke porazila princa Hildburghausena također postoje krajnje nerealne vijesti "dobro obaviještenih izvora“, ovaj put dubrovačkih: do 70.000 boraca bosanske vojske, izginulo do $15.000 .{ }^{17}$

Defter inače daje mnogo detaljnih podataka o količinama provijanta i broju konja, kako borbenih, tako i tovarnih, što tek treba kliometrički obraditi. Zapravo se radi o troškovniku nastalom djelomice i nakon opsade Sinja (neispravni topovi nakon opsade bili su prebačeni u Livno, trošak za plaću majstoru za popravak zatvarača fol. 16. datum 8. R. (Ramazan) 1127. = 7. 9. 1715.).

Prilog 1: transkripcija fermana o Tatarima (BOA, İE_AS___00067_06061_001):

Şah Ahmed bin Mehmed han el-muzaffer da'ima!

1. kıdvetu-l-emacid ve-l-'ayan Isakça anbar emini zide mecduhu tevkic-i refic-i hümayun vasıl olıcak maclum ola ki: haliyen Kırım hanlarından cenab-i emaret-meab-i iyalet nisab-i secadet eknab bi-l-ficl Kirım hanı olan Kaplan Giray han

2. damet meabehu macrifet ile gerek sefer-i hümayunuma me'mur sultan ile macan gelecek 5000 nefer ve gerek Bosna canibine me'mur olan sultan ile gelecek 5000 nefer Tatar 'askeri inşa Allahu tecala Tuna'yı mururlerinde sene-i sabika üzere

3. toptan bir mikdar zehire verilmek lazim gelip zikr olunan casker-i Tatar üzerlerine me'mur olan sultan ile han kışlağından kalkıp Bogdan ve Eflak memleketleri kuralarına uğramayıp ve re ayayı ruhsat etmeyip Bosna'ya

4. gidecekler Tatarlık'dan Tulça veyahud İsakça geçidinden Tuna'yı ubur ve Niğbolu havalisinde güzar edip Sofya üzerinden doğru Bosna'ya gitmeleri üzere karar verilip ve sefer-i hümayunuma me'mur olup ordu-yu hümayunuma gelecekler dahı

5. Tuna'yı Tulça iskelesinden geçip Dobruca içinde murur ve Filibe üzerinden Yenice'ye ve Yenice'den Kızıl Deli suyundan güzar ve Siroz ve Dirama'da ordu-yi hümayunumun geçtiği Uluyolu çıkıp ordu-yu hümayunuma mulaki olmak üzere olmakla

7 Ruža Radoš, Namjesnik Bosanskog ejaleta Ali-paša Hekimoglu (1736. - 1748.) i Dubrovačka Republika, Zagreb 2017. (doktorska disertacija), str. 101-102. Vijesti o Ali-pašinoj vojsci govore i o 40.000 ljudi, a izginulo bi i 15.000 . 
6. inşa Allahu tecala Bosna'ya gidecek 5000 Tatar caskeri için bir defa a 200 re's $^{c}$ gav ve 500 koyun ve 400 kile şacir ve 200 kantar peksimet ve me'mur olan sultan için dahı 15 kile pirinç ve 60 vukiye rugan-ı sade

7. mucacelen tedarik ve hazır ve amade etdirilip Bosna canibine me'mur casker-i mezbur Tulça veyahud İsakça geçidinden Tuna'yı 'ubur eylediklerinden zehair-i mezbur gidenlere sultan macrifet ile teslim ve sefer-i hümayunuma me'mur olan 5000 nefer dahı kezalike nehr-i Tuna'yı Tulça iskelesinden

8. 'ubur eylediklerinde anlar için dahi 200 re's gav ve 500 koyun ve 400 kile şacir 200 kantar peksimet ve me'mur olan sultan için dahı 15 kile pirinç ve 60 vukiye rugan-i sade ta ${ }^{c}{ }^{c i l}{ }^{c} a l a ' t-t^{c} c i l$ tedarik ve hazır ve amade etdirilip iskele-i mezbure geldiklerinde

9. yine sultan macrifet ile teslim etdirilmek fermanım olmağın imdi işbu emr-i şerifim vardığı sa'at kat'a te'hir ve tavakkuf eylemeyip ol mikdar zehireyi bir gün evvel tedarik ve hazır ve amade eyleyip iki tarafa me'mur casker-i Tatar geldikleri gibi sultanları macrifet ile

10. teslim ve kat ${ }^{c} a$ meks ve te'hir etdirilmeyip yerlerinden başka başka memhur temessük alıp hifaz ve narh-i ruzi ve siyer-i muslimin üzere bahalarını ashaba verip badehu taraf-i miriden sana verilmek üzere macrifet-i şerc ile mahz ve mahtum defter etdirilip defterleri

11. temessükler ile macan ordu-yu humayunuma irsal eylemek babında ferman-i calişanım sadir olmuştur. Buyurdum ki: vardıkta bu babda sadir olan emrim

12. üzere camel edip işbu emr-i şerifim vardığı sacat $k a^{c} a$ te'hir ve tavakkuf eylemeyip ol mikdar zehireyi bir gün evvel tedarik ve hazır ve amade eyleyip iki tarafa me'mur casker-i Tatar geldikleri gibi sultanlari macrifet ile teslim ve kat'a meks ve te'hir etdirilmeyip

13. yedlerinden başka başka memhur temessük alıp hıfaz ve narh-i ruzi ve siyer-i muslimin üzere bahalarını ashabına verip badehu taraf-ı miriden sana verilmek üzere macrifet-i şercle mahz ve mahtum defter etdirilip defterlerin temessüklerile macan ordu-yu hümayunuma irsal

14. eyliyesiz şöyle bilesiz calamet-i şerife ictimad kılasız. Tahriren fi el-yevm 22 min şehr -i RA sene 1127. (27. 4. 1715.)

15. be yurt-u sahra-yı Ulufeciler ${ }^{18}$

18 Postaja na maršruti prije etape Hasköy/Haskovo. 
Prilog 2. BOA, İE_AS___00067_06061_00119: U ovom fermanu o Tatarima brojka od 5.000 nekoliko se puta ponavlja, pa može izgledati kao da se radi o zbrajanju, no zapravo se kaže da se još ne zna hoće li (svi) oni, njih dvaput po 5.000, ići na jednu ili na drugu frontu.

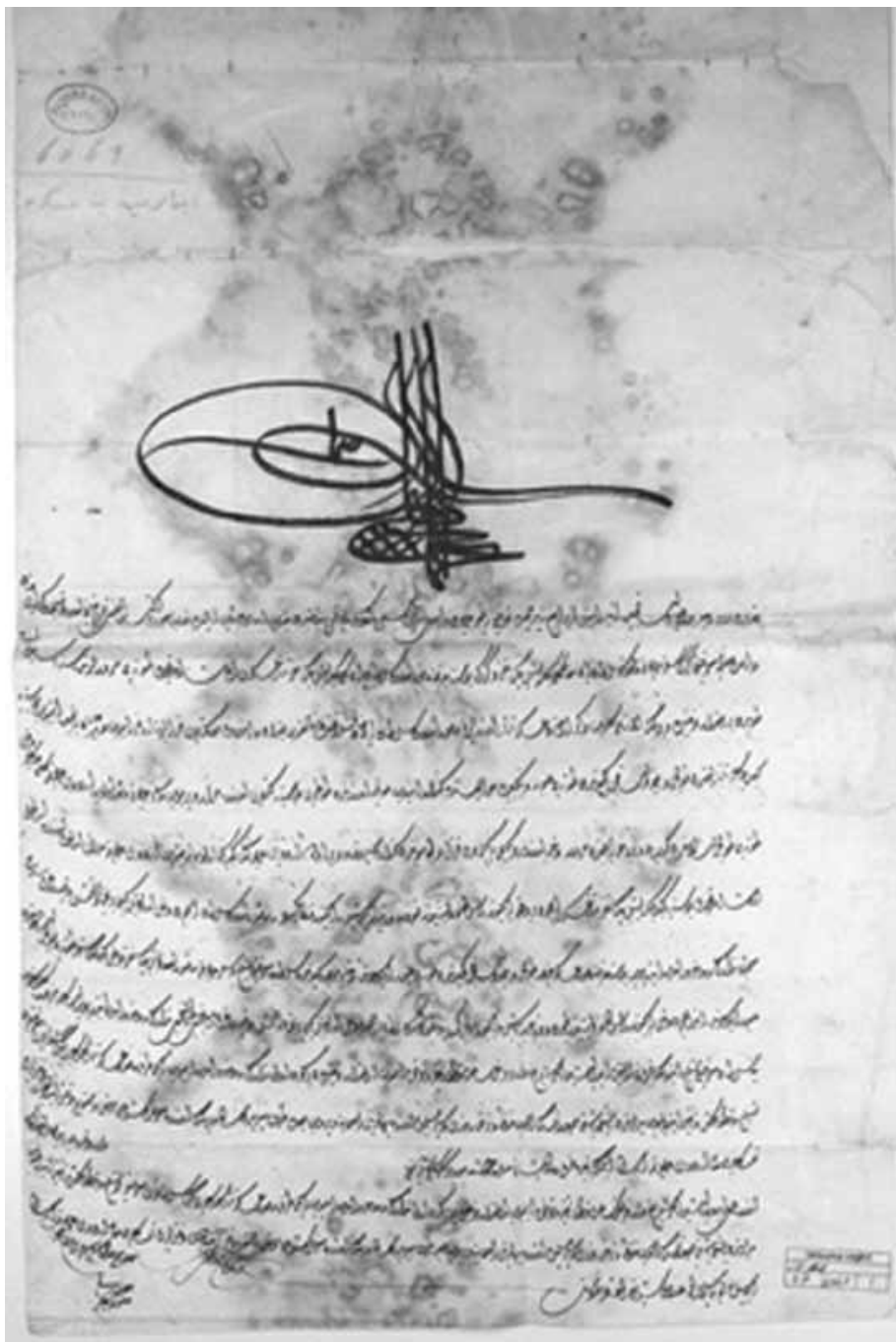

9 Kratka rekapitulacija fermana nalazi se pod istom signaturom, redni broj 003. 
Prilog 3. Defter troškova Mustafa-paše BOA, D_BŞM_d_01275_A_00004, brojno stanje i vrsta trupa izvan Bosanskog ejaleta. Zapis na fol. 4 datiran je 13. Šabana 1127. (14. kolovoza 1715.), dakle među brojnim izvješćima s raznih strana nema vremenski bližeg! Konstatacija da su nabrojeni vojnici koji su bili angažirani „za vrijeme opsade tvrđave Sinj“ sugerira da je zapis nastao takoreći u trenutku odluke da se prekine opsada (,temeljem naredbe/bujuruldije seraskera Mustafa-paše "). Napokon, „Mustafa-pašin defter" donosi i mnoštvo podataka oko provijanta, tovarnih konja i slično, te bi ga i iz tog aspekta vrijedilo analizirati.

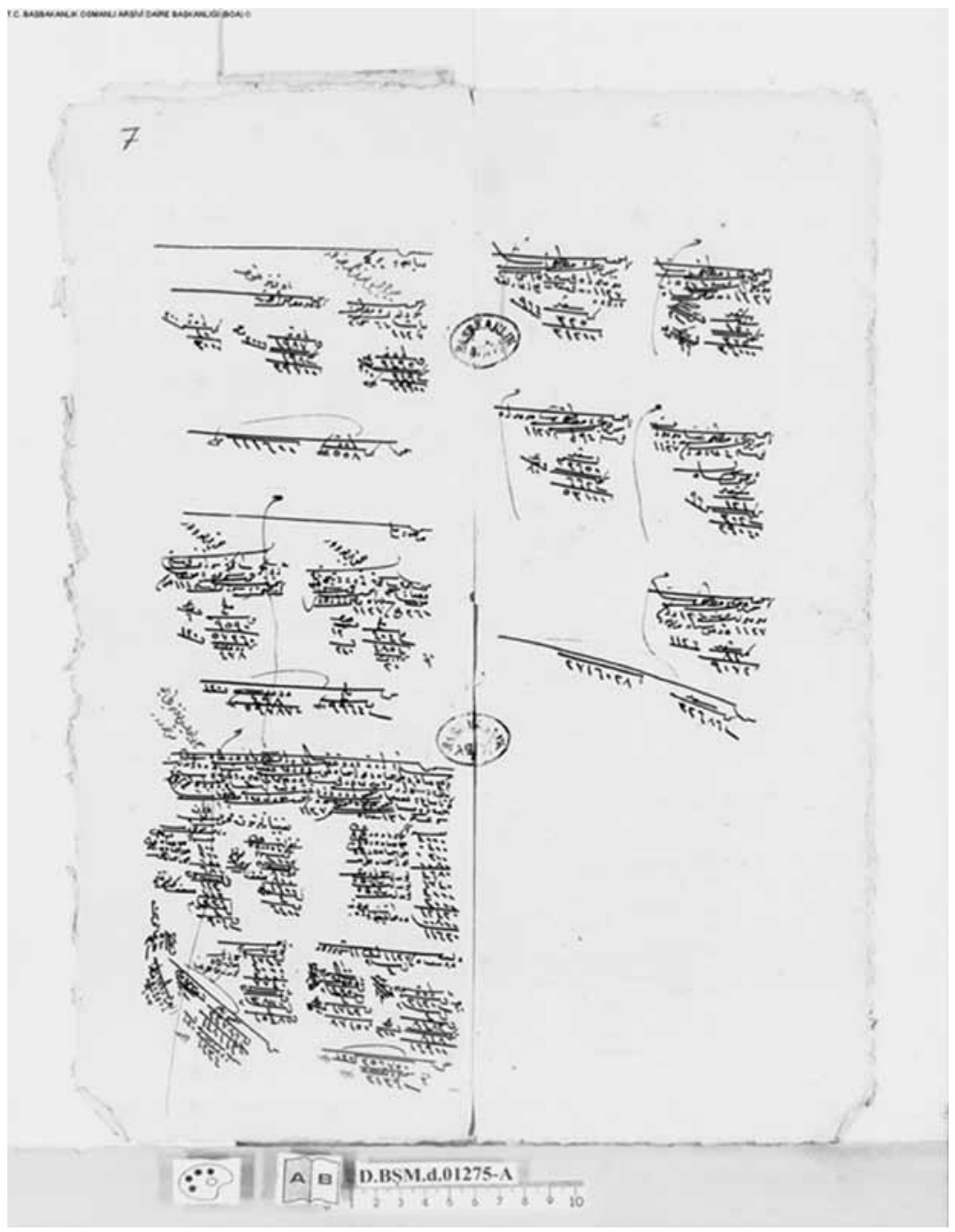


Ovdje spomenuti broj od 11.620 „nebosanskih“ vojnika valja uvećati za poznati broj Tatara, vjerojatni broj bosanskih snaga i pretpostavljene pomoćne odrede. To će dati oko 33.000 s još 6.000 - 7.000 pomoćnog osoblja. Albanci (2.000) „kriju“ se pod stavkom „levente pješaci Tahir-paše“, što odgovara „Mahmutbegoviću" po mletačkom izvješću = Tahir-paša Mahmutbegzade, guverner oblasti Dukađin (Metohija). Pitanje je je li u opsadi Sinja uopće $u$ znatnijoj mjeri sudjelovala bosanska vojska kao polovica ukupne sile. Ako su glavnu ulogu imali turski i razni balkanski levente prikupljeni „s kraja svijeta“, lakše je shvatiti osmanski poraz.

\section{Izvori i literatura}

\section{Izvori:}

Başbakanlık Osmanlı Arşivi (Arhiv predsjedništva vlade, Istanbul)

1. Ibnülemin, Askeri İE_AS_00067_06061

2. Defter-i Başmuhasebe D_BŞM_d_01275_A

3. Maliye den Müdevver MAD 10301

\section{Literatura:}

Lovorka Čoralić - Nikola Markulin, Bitka za Sinj 1715. godine, Zbornik Odsjeka za povijesne znanosti Zavoda za povijesne i društvene znanosti Hrvatske akademije znanosti i umjetnosti, Zagreb 2016., 147.180.

Ruža Radoš, Namjesnik Bosanskog ejaleta Ali-paša Hekimoglu (1736 - 1748) i Dubrovačka republika, Zagreb 2017. (doktorska disertacija), 368 str. 


\section{Summary}

On the Troop Strength of Ottoman Army Invading Sinj and Zagora in 1715, According to Turkish Sources

This article is a preliminary report on the analysis of the Ottoman sources about the campaign in Dalmatia and the siege of Sinj in 1715 in particular. At the present moment it seems that these sources confirm the assumption that the Ottoman forces in Dalmatia had a size of only a half of the number claimed by some Venetian intelligence reports, while only a quarter of the supposed total had been directly engaged in the siege.

Keywords: Sinj 1715.; Ottomans; army setup; logistics; Prime Ministry Archives Istanbul. 
